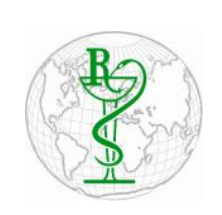

INDO GLOBAL JOURNAL OF

PHARMACEUTICAL SCIENCES

ISSN 2249- 1023

\title{
Drug Therapy Problems \& Contributing Factors Among Patients with Cardiovascular Diseases in Felege Hiwot Referral and Jimma University Specialized Hospital, Ethiopia
}

\author{
Gobezie Temesgen Tegegne ${ }^{1 *}$, Belay Yimamm ${ }^{2}$, Elias Ali Yesuf ${ }^{2}$ \\ ${ }^{1}$ Ambo University, College of Medicine \& Health Science, Department of Pharmacy, Ethiopia \\ ${ }^{2}$ Jimma University, College of Medicine \& Health Science, Ethiopia
}

Address for Correspondance: Gobezie Temesgen Tegegne, gob.ju2006@gmail.com, gobepharm@ymail.com

\begin{abstract}
Drug therapy problem is a new concept developed around 1990s. It results in increased morbidity and mortality. It is also a common scenario in chronic non communicable diseases, like cardiovascular diseases. Although pharmacotherapy in cardiovascular diseases can improve patient outcome, its benefit can be compromised by drug-related problems. The objective of the research is to characterize the prevalence of drug therapy problems and contributing factors among hospitalized patients with cardiovascular diseases in Felege Hiwot Referral and Jimma University Specialized hospital. Hospital based general cohort study design was used. All admitted patients with cardiovascular disease/s, in Felege Hiwot Referral and Jimma University specialized hospital were included. Most of the data were collected from patient card. Pharmacists in collaboration with a nurse were involved in collecting the data. The data were analyzed using SPSS version 20.0 Descriptive, logistic and linear regressions were used. P value of less than 0.05 was considered statistically significant to study association between risk factors and drug therapy problems. The most common cardiovascular disease encountered were hypertensive heart disease $(27,27.83 \%)$, rheumatic heart disease $(24,24.74 \%)$ and, functional heart failure and cor pulmonalae $(24,24.74 \%)$. A total of 164 number of DTPs were identified with the mean number of DTP was $1.69 \pm 0.993$. Most of the patients had drug therapy problem. Presence of heart failure (AOR: 8.001) had significant association. Number of co morbidity had significant association with number of DTPs while number of drugs didn't. As the number of co morbidity increases by one unit, there is $28.2 \%$ increase in number of DTP. (C) 2014 iGlobal Research and Publishing Foundation. All rights reserved.
\end{abstract}

KEYWORDS: Drug Therapy Problems; Cardiovascular Diseases; Pharmaceutical Care; Heart Failure.

\section{INTRODUCTION}

The availability of large number of medicines and the constant efflux of new information make them practically impossible for any health care professional to be updated in all aspects. Hepler and strand define pharmaceutical care as, 'the responsible provision of drug therapy for the purpose of achieving definite outcomes which improve the patient's quality of life' (1).
The philosophy around optimizing the outcomes of pharmacotherapy and pharmaceutical care lead to the concept of drug therapy problems (DTPs). According to Pharmaceutical Care Network Europe (PCNE) classification volume 6.2, drug therapy problems is 'an event or circumstance involving drug therapy that actually or potentially interferes with desired health outcomes '(2). 


\section{Indo Global Journal of Pharmaceutical Sciences, 2015; 5(1): 26-39}

Drug therapy problem has not achieved uniform meaning in most of the published articles. Hepler used the terms like drug-related problem, drug-treatment failure, and pharmacotherapeutic problem in one article to describe DTPs (3). Other researchers used the term medication errors, which is the error in the hospital medication use process (4-5). Therefore, it may be more appropriate to use the term 'drug-therapy problems. (4). It is relatively common in hospitalized patients and can result in patient morbidity and mortality, and increased costs (6).

According to Robert J. Cipolle text book of pharmaceutical care practice (third edition), there are seven basic categories DTPs. The first two categories of drug therapy problems (unnecessary drug therapy and need additional drug therapy) are associated with the indication. The third and fourth categories of drug therapy problems (need additional drug product and too low dose) are associated with effectiveness. The fifth and sixth categories of drug therapy problems (adverse drug reaction and too high dose) are associated with safety. The seventh category deals with patient compliance. This order is significant in that it describes the rational decision making process of the pharmacotherapy (7). The drug related problems (DRPs) and their possible causes will be identified from the patients' medical records, with reference to the standard guidelines and established literatures.

Epidemiologic transition which is taking place in every part of the world, among all races, ethnic groups, and cultures has resulted in the global rise in cardiovascular disorders (CVD) (8-9). Cardiovascular diseases account for $7-10 \%$ of all adult medical admissions in African hospitals, heart failure contributing to $3-7 \%$ (10-11). As a result of progressive urbanization and westernization in sub-Saharan Africa the spectrum and pattern of cardiovascular diseases along with their risk factors are also increasing (12).

Advancing age ( $>/=40$ years), diabetes mellitus, obesity, positive family history of diabetes, hypertension and dyslipidaemia are significant risk factors for developing cardiovascular diseases (13).

\section{STATEMENT OF THE PROBLEM}

Drug related problems are of a major concern in health care because of increased cost, morbidity and mortality. The cost of drug related morbidity and mortality exceeded $\$ 177.4$ billion in 2000 of total costs, followed by longterm-care admissions, which accounted for $18 \%(\$ 32.8$ billion) (14-15).
Classen DC. et'al (1997) found that among hospitalized patients that, adverse drug event (part of DTP) is associated with prolonged length of stay, increased economic burden, and an almost 2-fold increased risk of death $(16,17)$.

Drug therapy problems are the dominant reasons for admission. A retrospective cross-sectional study in Singapore showed that $71.9 \%$ of DTPs resulted in admission (18), while from a prospective multicenter study by Leendertse AJ et'al , among 13,000 unplanned admissions, $714(5.6 \%)$ were medication related, but $46.5 \%$ of these admissions were potentially preventable (19).

A review of the literature concerning DTPs has shown that $28 \%$ of all emergency department visits were medication-related, including adverse events of which $70 \%-90 \%$ were preventable $(20-21)$.

Computerized physician order entry (CPOE) has been shown to decrease medication errors by $55-80 \%$, but it is a common even after implementation of CPOE (22-23).

Other researchers try to study the use of single-pill formulations to simplify the medication regimen and to manage the patient appropriately by avoiding adverse effects in elderly patients with hypertension and comorbid diabetes (24), but the preparation of such formulation is difficult and the manufactured product is costly.

An interesting observation about the studies relating to DTPs is that there exists little data on comprehensive DTPs among hospitalized CVD patients in general. So far, most studies published addressed either DTP admissions to hospitals, or focused only on ADRs among hospitalized patients (25) (26).

A retrospective cohort study of medication-related problems occurring in patients admitted to an adult, innercity Australian teaching hospital conducted over twoyears showed that five factors were significantly associated with medication-related problems: female age of 18-50 years, single marital status, mental and behavioral problems, and a co morbidity index score of at least one (27) (28).

The study in Jordan showed that, most frequent reasons for admission were cardiovascular diseases $(10.7 \%)$, chest infection $(5.0 \%)$, acute asthmatic attack $(2.7 \%)$ and others (29). Cardiovascular diseases are the number one cause of death globally, more people die annually from CVDs than any other causes (8). Not only CVDs are having higher mortality, but also the drugs used for management of CVD causes greater DTPs (30). 
Indo Global Journal of Pharmaceutical Sciences, 2015; 5(1): 26-39

Most developing countries will experience the double burden of pre-transitional and post-transitional disease (9). Although HIV/ADIS is the leading cause of death in the sub Saharan region, CVD is the second leading killer over the age of 30 year (31-32). The potential costs of CVDs epidemic for African countries are staggering. It is estimated to cost (direct and indirect) $\$ 300$ billion annually in USA, equal to the entire gross domestic product of the African continent. The growing CVDs epidemic in Africa will increase already unacceptable levels of inequity in access to health care services (31).

The study in public and private hospital in Addis Ababa showed greater than half of the deaths were due to cardiovascular diseases (32). This shows appropriate management should be used to decreases such problem. On the hand other researcher found, even single-disease management does not appear promising as a strategy to care for patients (33).

\section{The conceptual frame work}

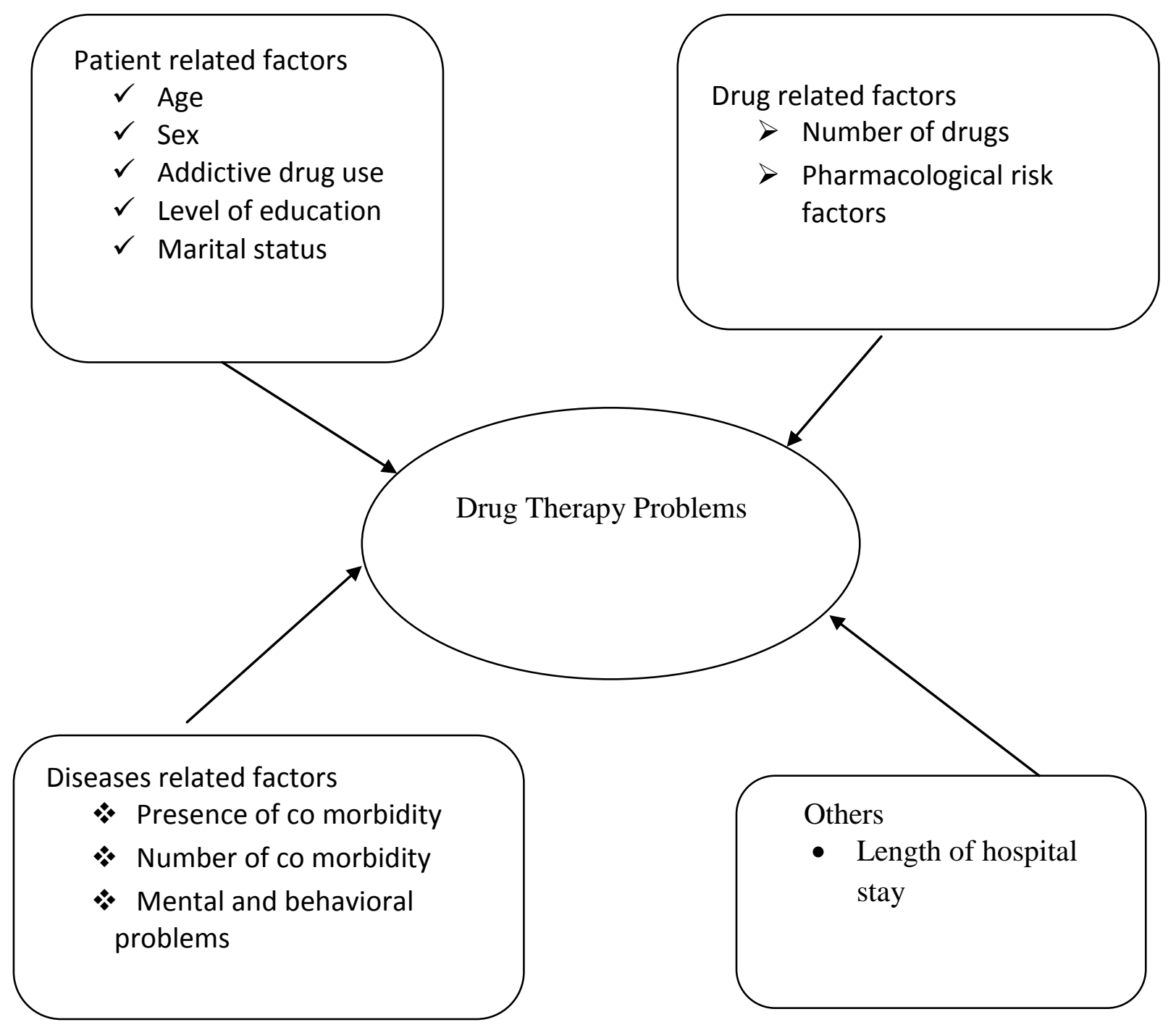

Figure 1: Conceptual Frame Work Showing Factors Involved In Drug Therapy Problems 


\section{SIGNIFICANCE OF THE STUDY}

Awareness of drugs carrying a high risk for DTPs, are important elements of drug therapy and may contribute to diminishing drug-related morbidity and mortality. Drug therapy problem among cardiovascular diseases will lead health care professionals to optimize drug therapy that may influence health expenses, save lives, improves health, reduces morbidity and increases quality of life.

From this research unique predictors of potential medication related problems identified, this facilitates systematic medication screening and treatment planning. Since early identification of the types and patterns of DRPs and the factors associated to them may enhance the prevention and management of DRPs. Categorizing and identifying drug related problems will also enable the practitioner in collaboration of the patient to construct a better care plan.

It would be much better to prevent drug related problems than to correct them, but this is not always possible because of the complexity of pharmacotherapy, lack of training and knowledge of health care providers and the behavior of the medicine users so that a more comprehensive study of DRPs in hospitalized patients should be done to provide valuable insights for the healthcare professionals trying to reduce the incidence of DRPs and the result can also be used as a base line information to establish guide lines and influence decision makers regarding DTPs, since it is an emerging concept on safe use of medication in the health care management.

Generally the result of this study will have good impact on the clinical practice among CVD patients.

\section{OBJECTIVES OF THE STUDY}

\section{General objective:}

To know drug therapy problems and contributing

factors among hospitalized patients with cardiovascular diseases in FHRH and JUSH

\section{Specific objectives:}

1. To measure the percentage of each types of drug therapy problems on cardiovascular diseases

2. To determine predictors for the presence of DTP

3. To determine the odds of DTPs among CVD patients with heart failure

\section{Research hypothesis}

1. The number of drug therapy problems doesn't vary based on the number of co-morbid CVD diseases.

2. The number of drug therapy problems doesn't vary based on the number of drugs used.

\section{METHODS}

\section{Study area and period}

The study was carried out among admitted patients with CVD in Felege Hiwot Referral and Jimma University Specialized hospital. FHRH is one of the referral hospitals in North
Eastern Ethiopia. It is found in Bahir Dar town, which is located approximately $578 \mathrm{~km}$ northwest of Addis Ababa. The hospital has a total of 284 beds. It has also 275 technical and 187 administrative staffs. The hospital serves the people of East and West Gojjam, Bahir Dar town and its surroundings, awi zone and south Gonder. The study was conducted from 03-29 March 2013 EC.

The study was also conducted in JUSH, which is located in Jimma city of Oromia regional state far $350 \mathrm{~km}$ in south west of Addis Ababa. It provides health services through its nine medical and other clinical and diagnostic centers for approximately 9000 in patients and 80,000 out patients each year with a bed capacity of 450 and a total of 550 staff. The study conducted for 15 days from 8-23 May 2013 in internal medicine ward.

\section{Study design}

Hospital based general cohort study design was used.

\section{Population}

\section{Source and Sample population}

It includes patients admitted with cardiovascular diseases in FHRH and JUSH during the data collection period.

\section{Inclusion and exclusion criteria}

\section{Inclusion criteria}

Patients admitted with cardiovascular diseases

\section{Exclusion criteria}

- Unconscious and patients who have no care giver that facilitates communication with the interviewer (Intensive care patients)

- Those not willing to participate

- Those who fail to buy the prescribed drugs

\section{Sample size and sampling technique}

The sample size was depending on the number of patients admitted during data collection time. Convenient sampling technique was used as per the data collection period and inclusion criteria.

\section{Variables}

\section{Independent variable}

Co-morbidity, number of drugs, age, sex, level of education, duration of hospital stay, heart failure, 


\section{Indo Global Journal of Pharmaceutical Sciences, 2015; 5(1): 26-39}

Chronic kidney disease, Diabetes Mellitus, Hypertensive heart disease, Rheumatic heart disease, addictive drug use,

\section{Dependent variables}

- Presence of Drug Therapy Problem

- Number of Drug therapy problems

\section{Data collection procedures}

Data collection was undertaken from 03-29 March 2013 in FHRH and from 8-23 May 2013 in JUSH. Data were collected through medical record reviews of patients using a prepared standard checklist and structured questionnaire. The structured questionnaire was translated to their local language. The content of the checklist include patient details, investigations, procedures, current and past medication and diseases conditions. Other like biochemistry and hematology results were also found. The contents of standard questionnaire include social history, drug and diseases related information. Two pharmacists, who took clinical pharmacy in service training, and one Nurse with bachelor degree, were involved to collect the data.

The first working diagnosis after one day of admission was taken as a provisional diagnosis for the patient disease condition. The patient was followed till discharge. Within these time interval, study subjects' symptoms, clinical and laboratory values were recorded to predict adverse drug reactions. Drug related problems were identified by evaluating the appropriateness of prescriptions in terms of indication, dosage, safety and efficacy. Finally the existence of DTPs was identified using Ethiopian guide line, European society of cardiology and American heart association. This was done by principal investigator and recommendations were forwarded to physicians.

\section{Data quality management}

Pre test study was done among 10 patients before two days of data collection period to check for the uniformity and understandability of the questionnaire, and other purposes. The data collectors were trained for two days on how to collect the data. The patient card number and phone number (if the patient has) was used, to check for if there is invalid and incomplete pertinent response. Supervisor was strictly supervising the data collectors daily and the principal investigator was reviewing all filled format daily so that any suggestion regarding to cardiovascular diseases pharmacotherapy is given.

\section{Data analysis}

The data was cleaned, coded, entered and analyzed in SPSS 20.0. Categorical variables were described by frequencies and percentages, and continuous variables were described by means and standard deviations. The relationship among age, gender, number of drugs and co morbidities, and heart failure with presence of DTP was seen in logistic regression while the relationship among number of drugs and co morbidities with number of DTPs were analyzed using linear regression model.

For other variables correlation was tested. Statistical analysis using Anova was done for different age groups. Probability values less than 0.05 was accepted as statistically significant and for simple logistic and linear regression, $p$ values $<0.25$ is considered for further multiple logistic regression analysis.

\section{Ethical consideration}

Formal letter was obtained from Research Ethics Committee of Jimma University and submitted to FHRH and JUSH, so the letter was given to the hospitals and they allowed us to do the research. Written consent was taken so that the patient was willing to give his/her medical information. Patient should be assured that lack of willingness to involve in the study will not affect the service they get from the hospital. If there is any drug therapy problem that affects the patients during the data collection time, the principal investigator tried to contact the physicians about those cases to solve the drug therapy. Any pertinent drug information was also provided to the patient during discharge. Patient confidentiality was ensured, thus name and address of the patient was not recorded in the data collection format. It was also told that his/her medical information was not disclosed to any external subjects/media so that the patient confidentiality was kept.

\section{Operational definitions}

A drug therapy problem: is any undesirable event experienced by a patient which involves, or is suspected to involve, drug therapy, and that interferes with achieving the desired goals of therapy, which can be identified using Ethiopian, WHO, European and the American heart association (AHA) cardiovascular diseases management guidelines except compliance and addictive drug use.

Adverse drug reaction: is any harmful and unintended effect associated with the drug till the patient is discharged.

Multi co-morbid disease: is a diseases condition when a patient has at least three diseases.

Poly-pharmacy: is considered when greater than or equal to four drugs are prescribed for the patient.

Poly - DTPs: is a DTP when the number of DTPs is greater than or equal to three DTPs.

Adherence" is drug taking behavior of a patient measured with Morisky scale in which when a patient 
Indo Global Journal of Pharmaceutical Sciences, 2015; 5(1): 26-39

says no at least for one of the question, he/she is noncompliant.
Addictive drug use: if a patient used any of the four social drugs at least three times per week.

Table 1: The Socio-Demographic Characteristics of Admitted CVD Patients from 03-29 March 2013 in FHRH and from 08-23 May 2013 in JUSH (N=97)

\begin{tabular}{|c|c|c|c|c|}
\hline No & Variable & & Frequency & Percent \\
\hline \multirow[t]{4}{*}{1} & \multirow[t]{4}{*}{ Educational status } & no schooling & 61 & 62.9 \\
\hline & & $1-8^{\text {th }}$ & 25 & 25.8 \\
\hline & & $9-12^{\text {th }}$ & 5 & 5.2 \\
\hline & & $>12^{\text {th }}$ & 6 & 6.2 \\
\hline \multirow[t]{4}{*}{2} & \multirow[t]{4}{*}{ Marital status of the patient } & Married & 65 & 67 \\
\hline & & Single & 24 & 24.7 \\
\hline & & Divorced & 7 & 7.2 \\
\hline & & Others (widow) & 1 & 1 \\
\hline
\end{tabular}

Table 2: Local Addictive Drug Use Among Admitted CVD Patients from 03-29 March 2013 in FHRH and from 08-23 May 2013 in JUSH $\left(N^{*}=97\right)$

\begin{tabular}{llll}
\hline S.no & Variables & Frequency & Percent \\
\hline 1 & Smoking cigarettes & 1 & 1.54 \\
2 & Chewing chat & 3 & 4.61 \\
3 & Drinking alcohol & 28 & 43.07 \\
4 & Drinking coffee & 55 & 84.61 \\
5 & Addictive drug use & 65 & $* 67$ \\
\hline
\end{tabular}

Table 3: Adherence Related issues using Morisky scale among admitted CVD patients from 03-29 March 2013 in FHRH and from 08-23 May 2013 in JUSH $(* \mathrm{~N}=97)$

\begin{tabular}{llll}
\hline S.No & Variables & Frequency & Rate \\
\hline 1 & Not take the medication during exacerbation & 12 & 15 \\
2 & Not remember to take the medication & 15 & 33.33 \\
3 & Not take the medication during recovery & 15 & 33.33 \\
4 & No caution is considered for medication & 18 & 40 \\
5 & Non-compliance & 45 & $* 46.36$ \\
\hline
\end{tabular}

Table 4: Type of Medication Use Among Admitted CVD Patients from 03-29 March 2013 in FHRH and from 08-23 May 2013 in JUSH (N=97)

\begin{tabular}{llll}
\hline S. No & Drugs used & Frequency & Percent \\
\hline 1 & Diuretics & 61 & 62.5 \\
2 & Antibiotics & 34 & 35.1 \\
3 & Spirenolactone & 25 & 25.8 \\
4 & ACEis & 19 & 19.6 \\
5 & Digoxin & 18 & 18.6 \\
6 & Anti coagulant & 14 & 14.43 \\
7 & Statin & 12 & 12.37 \\
8 & Calcium channel blockers & 9 & 9.3 \\
9 & Analgesics & 7 & 7.2 \\
10 & Hydralazine & 7 & 7.2 \\
11 & Magnesium sulphate & 5 & 5.2 \\
12 & BB & 5 & 5.2 \\
13 & PPIs & 4 & 4.1 \\
14 & Hypoglycemic & 3 & 3.1 \\
15 & Antihelment and anti paracite & 3 & 3.1 \\
\hline
\end{tabular}

ACEi=Angiotensinogen convertase inhibitors

BB = Beta blockers.

PPI $=$ Proton pump inhibitors 
Indo Global Journal of Pharmaceutical Sciences, 2015; 5(1): 26-39

Table 5: Type and Number of Specific DTP Category Among Admitted CVD Patients from 03-29 March 2013 in FHRH and from 8-23 May 2013 in JUSH

\begin{tabular}{|c|c|c|c|c|c|}
\hline $\begin{array}{l}\text { S. } \\
\text { No }\end{array}$ & DTP & & Specific DTP & Frequency & Rate \\
\hline \multirow{8}{*}{1} & \multirow{8}{*}{ Indication } & \multirow[t]{3}{*}{$\begin{array}{l}\text { Unnecessary } \\
\text { drug therapy }\end{array}$} & No medical condition & 2 & 2.32 \\
\hline & & & Treating avoidable ADR & 5 & 5.81 \\
\hline & & & Total & 7 & 8.14 \\
\hline & & \multirow{5}{*}{$\begin{array}{l}\text { Needs } \\
\text { additional drug } \\
\text { therapy } \\
\text { Total }\end{array}$} & Untreated indication & 43 & 53.75 \\
\hline & & & Preventive or prophylactic & 56 & 65.12 \\
\hline & & & Synergistic or potentiating action & 7 & 8.14 \\
\hline & & & Total & 78 & 90.69 \\
\hline & & & & 80 & 93.02 \\
\hline \multirow{6}{*}{2} & \multirow{6}{*}{ Effectiveness } & \multirow{2}{*}{$\begin{array}{l}\text { Needs different } \\
\text { drug product }\end{array}$} & More effective drug available & 12 & 13.95 \\
\hline & & & Total & 12 & 13.95 \\
\hline & & & Wrong dose & 1 & 1.16 \\
\hline & & & Frequency inappropriate & 4 & 4.65 \\
\hline & & $\begin{array}{l}\text { Dosage too } \\
\text { low }\end{array}$ & Total & 5 & 5.81 \\
\hline & & Total & & 17 & 19.77 \\
\hline \multirow{12}{*}{3} & \multirow{12}{*}{ Safety } & \multirow{5}{*}{$\begin{array}{l}\text { Adverse drug } \\
\text { reaction }\end{array}$} & Undesirable effect & 16 & 18.60 \\
\hline & & & Unsafe drug for patient & 2 & 2.32 \\
\hline & & & Drug interaction & 1 & 1.16 \\
\hline & & & Contraindication present & 1 & 1.16 \\
\hline & & & Total & 22 & 25.58 \\
\hline & & \multirow{6}{*}{$\begin{array}{l}\text { Dosage } \\
\text { high }\end{array}$} & Wrong dose & 9 & 10.46 \\
\hline & & & Frequency inappropriate & 2 & 2.32 \\
\hline & & & Duration inappropriate & 1 & 1.16 \\
\hline & & & Drug interaction & 1 & 1.16 \\
\hline & & & Incorrect administration & 1 & 1.16 \\
\hline & & & Total & 11 & 12.79 \\
\hline & & \multicolumn{2}{|l|}{ Total } & 27 & 31.39 \\
\hline
\end{tabular}

Table 6: Number of cardiovascular diseases diagnosed and presence of DTP among admitted CVD patients from 03-29 March 2013 in FHRH and from 8-23 May 2013 in JUSH (N=97)

\begin{tabular}{llcccc}
\hline S. & Disease & \multicolumn{2}{c}{ Number of patients } & \multicolumn{2}{c}{ presence of DTP } \\
\cline { 3 - 5 } & & Frequency(M) & Percent & $\begin{array}{l}\text { Frequency } \\
(\mathbf{m})\end{array}$ & Rate $(\mathbf{m} / \mathbf{M})$ \\
\hline 1 & Hypertensive heart disease & 27 & 27.83 & 22 & 81.48 \\
2 & Rheumatic heart disease & 24 & 24.74 & 22 & 91.67 \\
3 & FHF and CP & 24 & 24.74 & 23 & 95.83 \\
4 & IHD & 9 & 9.28 & 5 & 55.56 \\
5 & Cerebro vascular disease & 7 & 7.22 & 5 & 71.43 \\
6 & Vascular disease & 3 & 3.09 & 2 & 66.67 \\
7 & Others & 3 & 6.18 & 1 & 33.33 \\
\hline
\end{tabular}


Indo Global Journal of Pharmaceutical Sciences, 2015; 5(1): 26-39

Table 7: Presence of DTP in Relation to Number of Drugs and Co Morbidities Among Admitted CVD Patients from 03-29 March 2013 in FHRH and from 08-23 May 2013 in JUSH(N=97)

\begin{tabular}{lllllll}
\hline \multirow{2}{*}{ S.No } & Variables & \multicolumn{2}{c}{ Number of patient } & \multicolumn{2}{c}{ Rate of presence of DTP } \\
\cline { 3 - 6 } & & Frequency(M) & Percent & Frequency(m) & Rate(m/M) \\
\hline 1 & Number of drugs & $<3.5$ & 62 & 63.92 & 53 & 85.48 \\
& & $>/=3.5$ & 35 & 36.08 & 33 & 94.29 \\
2 & Presence of co morbidity & 80 & 82.7 & 73 & 91.25 \\
3 & Absence of co morbidity & & 17 & 17.8 & 13 & 76.47 \\
4 & Number of co morbidity & $<3$ & 74 & 76.29 & 64 & 86.49 \\
& & $>/=3$ & 23 & 23.71 & 22 & 95.65 \\
\hline
\end{tabular}

Table 8: Presence of DTP Among Co Morbid Illness Among Admitted CVD Patients from 03-29 March 2013 in FHRH and from 08-23 May 2013 in JUSH $(\mathrm{N}=80)$

\begin{tabular}{|c|c|c|c|c|c|}
\hline \multirow[t]{2}{*}{ No } & \multirow[t]{2}{*}{ Co morbid illness } & \multirow[b]{2}{*}{ Frequency $(\mathbf{M})$} & \multirow[b]{2}{*}{ Rate } & \multicolumn{2}{|c|}{ Rate of DTP presence } \\
\hline & & & & $\begin{array}{l}\text { Frequency } \\
\text { (m) }\end{array}$ & Rate $(\mathbf{m} / \mathbf{M})$ \\
\hline 1 & Pneumonia & 9 & 11.25 & 8 & 72.73 \\
\hline 2 & Urinary tract infection & 11 & 13.75 & 11 & 100 \\
\hline 3 & Diabtes mellitus & 2 & 2.5 & 2 & 100 \\
\hline 4 & Anemia & 10 & 12.5 & 9 & 90 \\
\hline 5 & Chronic kidney diseases & 6 & 7.5 & 6 & 100 \\
\hline
\end{tabular}

Table 9: Logistic Regression Result of Age, Gender, Heart Failure, Number of Drugs and Co Morbidity with Presence of DTP Among Admitted CVD Patients from 03-29 March 2013 in FHRH and from 08-23 May 2013

\begin{tabular}{|c|c|c|c|c|c|c|c|}
\hline \multicolumn{8}{|c|}{ in JUSH (N=97) } \\
\hline No & Variables & $\begin{array}{l}\text { Frequency } \\
(\%)\end{array}$ & P value & COR & B (slope) & $\begin{array}{l}\text { CI }(95 \%) \\
\text { lower }\end{array}$ & upper \\
\hline \multirow[t]{4}{*}{1} & Age & & 0.891 & & & & \\
\hline & $<19 \mathrm{yr}$ & $14(14.4)$ & 0.631 & 1.667 & 0.511 & 0.207 & 13.428 \\
\hline & $19-60 \mathrm{yr}$ & $61(62.9)$ & 0.758 & 1.296 & 0.26 & 0.248 & 6.771 \\
\hline & $>60 \mathrm{yr}$ & $22(22.7)$ & 1 & 1 & & & \\
\hline \multirow[t]{2}{*}{2} & Female & $47(48.5)$ & 0.668 & 1.317 & 0.275 & 0.374 & 4.643 \\
\hline & Male & $50(51.5)$ & 1 & 1 & & & \\
\hline 3 & Number of co morbidity & $80(80.08)$ & 0.038 & 0.511 & 0.324 & 0.271 & 0.964 \\
\hline 4 & Number of drugs & & 0.318 & 0.792 & -2.33 & 0.502 & 1.251 \\
\hline \multirow[t]{2}{*}{5} & Heart failure & $61(62.9)$ & 0.005 & 9.833 & 2.286 & 1.988 & 48.628 \\
\hline & No & $36(37.1)$ & 1 & & & & \\
\hline $6^{*}$ & Number of co morbidity & & 0.113 & 30.58 & -0.544 & 0.296 & 1.137 \\
\hline \multirow[t]{2}{*}{$7 *$} & Heart failure yes & $61(62.9)$ & 0.012 & 8.001 & 2.08 & 1.579 & 40.55 \\
\hline & No & $36(37.1)$ & 1 & & & & \\
\hline
\end{tabular}

*=multiple logistic regression result, * Correlation matrix $=0.079$ 
Indo Global Journal of Pharmaceutical Sciences, 2015; 5(1): 26-39

Table 10: Linear Regression Results of Number Drugs and Co Morbidity with Number of DTPs Among Admitted CVD Patients from 03-29 March 2013 in FHRH and from 08-23 May 2013 in JUSH

\begin{tabular}{|c|c|c|c|c|c|c|c|c|}
\hline \multirow[t]{2}{*}{$\begin{array}{l}\text { S. } \\
\text { no }\end{array}$} & & \multirow[t]{2}{*}{$\begin{array}{l}\text { Standardized } \\
\text { coefficient (B) }\end{array}$} & \multirow[t]{2}{*}{$P$ value } & \multirow[t]{2}{*}{$\begin{array}{l}R \\
\text { square }\end{array}$} & \multirow[t]{2}{*}{$\begin{array}{l}\text { R square } \\
\text { change }\end{array}$} & \multirow[t]{2}{*}{ F change } & \multicolumn{2}{|c|}{$95 \% \mathrm{CI}$} \\
\hline & & & & & & & Lower & Upper \\
\hline 1 & $\begin{array}{l}\text { Number of co } \\
\text { morbidity }\end{array}$ & 0.312 & 0.002 & 0.097 & 0.088 & 10.245 & 0.086 & 0.367 \\
\hline 2 & Number of drugs & 0.190 & 0.062 & 0.036 & 0.026 & 3.575 & -0.006 & 0.252 \\
\hline $3 *$ & $\begin{array}{l}\text { Number of co } \\
\text { morbidity }\end{array}$ & 0.282 & 0.011 & 0.101 & 0.082 & 5.296 & 0.049 & 0.361 \\
\hline $4^{*}$ & Number of drugs & 0.069 & 0.523 & - & - & - & 0.816 & 1.226 \\
\hline
\end{tabular}

*=multiple linear regression result, $\mathrm{VIF}=\mathbf{1 . 2 2 6}$ and Tolerance $=0.816$

\section{RESULTS}

Socio-demographic characteristics of the study population

A total of 97 cardiac patients were included, $76(78.35 \%)$ of them were from FHRH. $51.5 \%$ of them were males while $67 \%$ and $62.5 \%$ of the patients were married and illiterate respectively (Table 1 ). The mean age was $41.7 \pm 21.8$ years while the minimum age was 0.8 year and the maximum was 90 years.

Most of $(65,67 \%)$ the patients used any of the four types of social drugs (coffee, alcohol, chat or cigarette). Most of the patients $(55,84.61 \%)$ drank coffee (Table: 2$)$. Coffee and alcohol $(18,18.5 \%)$ were among the common combined addictive drugs used.

According to validated Morisky scale, 45 (46.4\%) number of patients weren't adhere to the medication. $18(40 \%), 15$ $(33.33 \%)$, and $15(33.33 \%)$ number of patients didn't consider caution to take the medication, not taking the medication during recovery and forget to take the medication respectively (Table 3). Large number of patients admitted in FHRH (45, 46.4\%) was noncompliant.

Provisional diagnosis and medication use status of CVD patients admitted in FHRH and JUSH

The mean number of hospital stay was $5.69 \pm 3.8$ days (from 0-19days) used to treat some patients on the ward. A maximum of six number of co morbidities were seen, while the mean number of co morbidity was $1.82 \pm 1.34$. The most common diseases encountered during the data collection period were hypertensive heart diseases (27, $27.84 \%)$, rheumatic heart diseases $(24,24.74 \%)$ and functional heart failure and cor pulmonalea $(24,24.74 \%)$
(Graph: 2). Heart failure $(64,65.9 \%)$ was the common syndrome that accompanied the admission of greater number of patients.

A total of 307 numbers of drugs were used. The mean number of drug was $3.16 \pm 1.54$ per patient. A maximum of seven numbers of drugs were prescribed. Diuretics (61, $62.1 \%)$ and antibiotics $(34,35.1 \%)$ were the commonly used drug (Table: 4)

Type and number of Drug therapy problems among CVD patients admitted in JUSH and FHRH

A total of $86(88.66 \%)$ patients had one or more DTP/s. 15 out of 21 and 71 out of 76 patients admitted in JUSH and FHRH respectively had DTP while $2(13.34 \%)$ and $14(19.72 \%)$ numbers of patients admitted in JUSH and FHRH respectively had poly DTPs. 1.31 and 1.48 times higher occurrence of DTP and poly DTP respectively were found in FHRH than JUSH. However, independent T-test showed there is no variability $(\mathrm{p}=0.058)$ and mean difference $(p=0.36)$ with the occurrence of drug therapy problems between two hospitals. There was a total of 164 DTPs identified. The mean number of DTP was $1.69+$ 0.993 per patient. The maximum number of DTPs was four (Graph: 2). Most of the patients (38, 39.2\%) had two DTPs.

There were 80 (90.69), 45 (46.4\%), 27 (31.39\%) and 17 $(19.77 \%)$ number of patients had indication, noncompliance, safety and effectiveness related drug therapy problems respectively. Indication was the major problem in JUSH $(61,80.26 \%)$ and FHRH $(19,90.48 \%)$. Most of the indication problem was need additional drug therapy $(78,90.69 \%)$, of which preventive $(43,53.75 \%)$ and untreated indication $(56,65.12 \%)$ were common. The 


\section{Indo Global Journal of Pharmaceutical Sciences, 2015; 5(1): 26-39}

common untreated indications were anemia $(13,16.25 \%)$ and hypertension $(5,5.81 \%)$.

There were 17(19.77\%) numbers of DTPs among effectiveness related issues; of which more effective drug available $(12,13.95 \%)$ from need different drug product and inappropriate frequency (4) from dosage too low were the common DTP. A total of $12(13.95 \%)$ and $6(7.5 \%)$ number of patients had need different drug product and dosage too low problem respectively.

$27(33.75 \%)$ number of patients experienced safety related DTPs, of which $22(27.5 \%)$ and $11(13.75 \%)$ number of patients had undesirable effects and adverse drug reaction respectively. The most common undesirable effects are hypotension $(16,18.6 \%)$ and nasal bleeding (2).

Aspirin (1) and digoxin (1) were wrongly indicated for stage B heart failure patients. Aspirin and clopidogrel together is also indicated for one patient. Enalapril is indicated for first trimester pregnant. Frusemide was used as wrong dose (dose too high), while dexamethasone and digoxin were used as inappropriate frequency for some patients (table 5).

Among 97 patients, 9 (9.28\%) of them showed different forms of allergy like vomiting (4), gastro-intestinal irritation (2) and constipation (2) before they were admitted for their cardiac case.

A total of $23(95.83 \%), 22$ (91.67) and $22(81.48 \%)$ number of patients with functional heart failure and cor pulmonalae, rheumatic heart disease and hypertensive heart disease respectively had DTP (Table 6).

Most patients had co morbidity and used more than one drugs. $62(63.92 \%)$ and $80(82.7 \%)$ number of patients used poly pharmacy and had co morbidity respectively of which 33(94.29) and 73 (91.25) number of patients with poly pharmacy and co morbidity respectively had DTP. Most of the patients $(22,95.6 \%)$ with multi co morbidity had DTP cases (table 7).

All patients with CKD (6), DM (2), and UTI (11) had DTP while anemia (10) and urinary tract infection (11, $11.25 \%$ ) were the common co morbidity (Table 8 ).

\section{The relationship between the determinant variables with drug therapy problems}

No correlation was observed between age $(\mathrm{p}=0.908)$, number of addictive drug use $(\mathrm{p}=0.188)$, length of hospital stay $(\mathrm{p}=0.534)$, number of co morbidity $(p=0.292)$, education status $(p=0.713)$ and number of drugs $(p=0.184)$ with the presence of drug therapy problems while age $(\mathrm{p}=0.202)$, sex $(0.007)$, length of hospital stay $(0.16)$, diabetes mellitus $(\mathrm{p}=0.928)$, chronic kidney disease $(p=0.054)$, rheumatic heart disease $(\mathrm{p}=0.205)$, hypertensive heart diseases $(\mathrm{p}=0.178)$, presence of co morbidity $(\mathrm{p}=0.203)$, education status $(\mathrm{p}=0.458)$, and addictive drug use $(\mathrm{p}=0.003)$ didn't also correlate with number of DTP except sex and addictive drug use.

Anova result showed there was no significant association between different groups of age $(\mathrm{p}=0.893)$ with presence of drug therapy problems.

Age, sex, number of drugs, number of co-morbidity and heart failure were analyzed using logistic regression model. By considering $\mathrm{p}<0.25$, number of co morbidity and heart failure were taken to go to multiple logistic regression. Patients with heart failure were 8.001 times risky to DTP than without it (table 9).

Number of drugs and number of co morbidity were tried to analyze using linear regression technique and they were candidates for multiple linear regression (Table 10).

Number of co morbidity was statistically associated with number of DTPs while number of drugs failed to show. As the number of co morbidities increased by one unit, $28.2 \%$ increase in number of DTPs was seen.

\section{DISCUSSION}

The most common CVD encountered were hypertensive heart disease $(27,27.84 \%)$, rheumatic heart diseases $(24$, $24.74 \%$ ) and functional heart failure and cor pulmonalae $(24,24.74 \%)$ where the study in Jordan showed, systemic hypertension $(38.47 \%)$ was the major diagnosis (29). Heart failure $(64,65.9 \%)$ was the common syndrome that caused higher number of patient admission.

Urinary tract infection $(11,13.75 \%)$, anemia $(10,12.5 \%)$ and pneumonia $(9,11.25 \%)$ were the common co morbidities, while in Jordan diabetes mellitus (37, $46.25 \%)$ and chronic renal failure $(15,18.75 \%)$ were the most common ones. Since infection is prevalent in most developing countries (29).

There were a total of 307 drugs with a mean of $3.16 \pm 1.539$ number of drugs per patient, which is smaller than the study in Jordan which had 13.14 per patient (1051 drugs) (29).

Diuretics (62.12\%), ACEi (19.6\%), and antibiotics (35.1\%)were the commonly used drugs while in Jordan the most commonly prescribed drugs were antihypertensive $(21.05 \%)$, anticoagulants and antiplatelets drugs (11.13\%) and antiulcer (8.84\%). This 


\section{Indo Global Journal of Pharmaceutical Sciences, 2015; 5(1): 26-39}

could be due to there were higher number of heart failure and rheumatic heart disease patients in this study (29).

Most of the admitted patients (86, 88.6\%) had DTP, which is similar to the study by Blix et'al and Andreazza et'al $(30,43)$.

A total of 164 numbers of DTPs were identified with the mean number of $1.69 \pm 0.993$ DTP per patient. The study in JUSH in internal medicine ward showed, there were 149 DTP with 3.014 DTP per patient, this variation can be due to the involvement of clinical pharmacy service since then. On the other hand in Jordan, 394 DRPs were identified, which correspond to 4.9 DRPs per patient (29, 42). In this study use of addictive drugs and compliance is not considered. This can cause the above variation.

The major DTP type was indication $(80,90.69 \%)$, from which need additional drug therapy was the common, while in Jordan efficacy and safety DTP types were the common; such difference can be explained with higher number of drug use in Jordan and can be due to there is no specific and comprehensive national CVD treatment guide line in Ethiopia. Mekonnen AB found unnecessary drug therapy was the common DTP ,of which no medical condition was the common while in this study unnecessary drug constituted lesser number of DTP since addictive drug use is not grouped as DTP(42).

Need additional drug therapy $(78,90.69 \%)$ is one of the most common DTPs. It was also common problem in the Mekonnen AB's $(34,70.83 \%)$ study in JUSH internal medicine ward. This can be due to the absence of specific and comprehensive disease management guideline (42).

The common untreated indications were anemia (13), hypertension (5), urinary tract infection (3), atrial fibrillation (2), and rheumatoid arthritis (1) respectively while in Jordan study anemia and dyslipidemia were the common (29).

There were 17 (19.77\%) patients with effectiveness related DTP, which is lesser than the study by Roberta SA (44) and Mekonnen AB (22) this might be due to the inclusion of all internal medicine admitted patient in the latter studies $(30,41,42)$.

Relatively higher number of safety related problems (22, 45.83\%) were found by Mekonnen AB than this study $(27,31.39 \%)$. This difference can be due to Mekonnen $\mathrm{AB}$ considers all internal medicine admitted patients or can be due to lesser involvement of pharmaceutical care services (42).

Mekonnen $\mathrm{AB}$ showed higher number of adverse drug events $(16,33.33 \%)$ and dosage too high $(12,8 \%)$ than this study $(22,27.5 \%$ and $11,13.75 \%)$, because all internal medicine cases were selected $(29,34)$.

The most common undesirable effects are hypotension $(16,16.5 \%)$ and nasal bleeding $(2,2.1 \%)$ respectively, which are similar in Al Salmi study (39). Hypotension is due to the use of high dose of frusemide and enalapril while the nasal bleeding is due to the use of high dose unfractionated heparin and warfarin $(37,44,45)$.

Using Morisky as adherence measuring parameter, 45 (46.4\%) number of patients was non-compliant. No caution considered while taking the medication was the major non-compliance issue; this can be due to dispensing associated error. Even though different measurement of adherence was used, 29 of the patients were noncompliant in the Mekonnen AB's study (42).

Aspirin (one) was indicated for stage B heart failure patient with out considering risk to benefit ratio because these patients had peptic ulcer disease. Aspirin and clopidogrel is also indicated for one patient even though such combinations are not accepted today due to severity of the combined adverse effect $(46,47)$. Enalapril is indicated for first trimester pregnant, even though it wasn't taken. It is contraindication to pregnant women (48). Frusemide was also indicated as tablet form for patient with severe peripheral edema.

ACEi, ciprofloxacin, and warfarin were among the most effective drug related DTPs, which should be used for some patients, but they were n't used during that time while some antibiotics, hydrochlothiazide, BB, and digoxin were not also used for some patients as synergistic effect to manage some indication. The most common drug categories which should be used as a preventive therapy were ACEi $(23,23.6 \%)$ and BB (20, $20.6 \%$ ). The benefit of ACEi cardiovascular diseases management are ventricular remodeling, norepinephrine release, vasoconstriction, sodium and water retention, and preventing myocardial fibrosis, myocyte apoptosis and cardiac hypertrophy, while beta blockers decrease ventricular mass, improve the sphericity of the ventricle, and reduce systolic and diastolic volumes (left ventricular end-systolic volume and left ventricular end-diastolic volume) $(44,46)$.

Lower dose of loop diuretics or by adding angiotensinogen II convertase enzyme inhibitors (dual benefit) can be used to prevent hypokalemia rather than using potassium chloride as a preventive therapy. Two out of five of them have taken digoxin (severe interaction is expected)(45).

Aburuz SM et'al identified cardiovascular and anti diabetic drugs were associated with presence of DTP while in this study all patients taking digoxin, statin and 


\section{Indo Global Journal of Pharmaceutical Sciences, 2015; 5(1): 26-39}

anticoagulant therapy, and most patients taking diuretics had DTP. On the other hand patients taking BB, NSAIDs and ACEi were highly associated with DTP in Koh (2005) study $(18,29)$.

The influence of age and gender was assessed by different studies. In this study age and gender can't influence independently the occurrence of DTP like Blix et'al study $(25,37)$, on the other hand Krahenbuhl-Melcher, A. showed females and elders were risky to DTP because of the different physiologic make up $(36,38)$.

Blix et'al and Koh found number of drug associated with the presence of DTP, while the mean number of drug use for Blix et'al was 4.2. On the other hand in this study number of drug couldn't independently associate with presence of DTP (mean drug use 3.16) $(25,43)$. The study in Jordan also found number of drugs and co morbidity had significant association with presence of DTP, which contradicts with this study result. This can be due to there are more number of drugs prescribed (three times) in Jordan (29).

Presence of co morbidity put a significant burden on the patient management (40), but it didn't associate with presence of DTP in this study. It might need other confounder to influence of occurrence of DTP. Caughey GE et'al study found multi-morbidity influence the presence of DTP as in this study $(\mathrm{p}=0.033, \mathrm{r}=(-0.217))$, but logistic regression couldn't show significant association $(25,35)$. Here most of the co-morbid illnesses were infection that needs antibiotics.

Zaman Huri found CVD is associated with presence of DTP. However, in this study, specifically heart failure is associated with presence of DTP. Heart failure patients had eight times risky than patients without it. This might be due to the use of more number of drugs to manage heart failure and most of the patients with heart failure had co morbidity(35).

Beers $\mathrm{MH}$ found patients stayed greater than two weeks had significant association with DTP, while in this study no co relation was observed between length of hospital stay $(p=0.534)$ with presence of DTP (39). This can be due to greater than half of the patients in this study stayed less than eight days.

Andreazza RS et'al found no schooling had correlation with DTP, like in this study $(\mathrm{p}=0.713)$. In Andreazza RS et'al higher number of drugs were prescribed, that made them difficult to take according to dispenser's information.

Viktil (2006) found number of DTP is linearly related with number of drugs i.e as one unit increase in number of drug, there is $8.6 \%$ increase in number of DTP, while in this study no association was observed. Such difference can be due to the use of higher number of drug per patient in Viktil study (49).

In this study number of co morbidity had significant association with number of DTP. As the number of co morbidity increases by one unit, there is $28.2 \%$ increase in number of DTP. This can be due to more number of drugs ought to use to manage those co morbidities. This might lead to occurrence of drug therapy problem.

More patients admitted in FHRH had greater DTP and poly DTP cases per patient than in JUSH; this can be due to the insufficient pharmaceutical care activities by pharmacists.

The present study has the following limitations. First, it remains unknown to changes in medication which leads to improvement in the health and well being of the patients because such outcome data was methodologically difficult to obtain. Second, decisions about pharmacotherapy in this area are difficult as current guidelines rarely address the complexity of multiple chronic conditions of patients with cardiovascular diseases. Third, small sample size, not using a random sampling method, and lack of a valid method in identifying DTPs and a panel to evaluate and discuss the DTPs if did not exist

\section{CONCLUSION}

The most common CVD encountered were hypertensive heart disease, rheumatic heart disease and functional heart failure and cor pulmonalae.

Most of the patients had DTP. The major DTP type was indication, from which need additional drug therapy was the common. No correlation was observed between age, number of drugs, number of co morbidity, number of addictive drug use, education and length of hospital stay with the presence of drug therapy problems.

Age, sex, number of drugs and co morbidities had no significant association with presence of DTP, but presence of heart failure had significant association.

Number of co morbidity had significant association with number of DTPs, while number of drugs didn't.

\section{RECOMMENDATION}

Drug therapy problem was high in both hospitals, so following recommendation were forwarded. 


\section{Indo Global Journal of Pharmaceutical Sciences, 2015; 5(1): 26-39}

$\checkmark$ MOH and FMHACA: To establish drug therapy problem guide line as per the national label to give quality pharmaceutical service for the patient

$\checkmark \mathrm{MOH}$ and FMHACA: To establish nationwide specific and comprehensive cardiovascular disease management guide line

$\checkmark \mathrm{MOH}$ and FMHACA: To effectively establish and develop pharmaceutical care services

$\checkmark$ Health care professionals : to educate patients to stop the use of social drugs and how to adhere to the prescribed medications

$\checkmark$ Researchers: to investigate the possible reason for indication problem

$\checkmark$ Researchers: to investigate the impact of sex and number of addictive drug use on number of DTPs.

\section{ABBREVIATIONS ACRONYMS}

ACE: Angiotensin converting enzyme inhibitors

ADR: Adverse Drug Reaction

BB: Beta Blockers

CKD: Chronic Kidney Disease

COPD: Chronic Obstructive Pulmonary Disease

CVD: Cardio-vascular Diseases

DM: Diabetes Mellitus

DRP: Drug Related Problem

DTPs: Drug Therapy Problems

FHRH: Felege Hiwot Referral Hospital

FMHACA: Food, Medicines and Health care Administration and Control Authority

HIV/AIDS: Human Immune Deficiency Virus/Acquired

Immune Deficiency Syndrome

JUSH: Jimma University Specialized Hospital

MOH: Ministry Of Health

NSAID: Non steroidal Anti-Inflammatory Drugs

PCNE: pharmaceutical care network Europe

USA: United States of America

\section{ACKNOWLEDGEMENT}

My greatest and an endless gratitude go to our almighty GOD then mother of fleshy word. Our appreciation goes to Fikertie Andu alem, Yayu Getie and Gojjam Temesgen and Gashaw Temesgen for your support. Our appreciation also goes to study participants, Felege Hiwot referral and Jimma University specialized hospital administrative and staff members for their cooperation. Finally we would like to express our sincere thanks to all my friends who gave me valuable idea to prepare this paper. Last but not least; we thank Jimma University for its fund.

\section{REFERENCES}

1. Hepler CD, Strand LM. Opportunities and responsibilities in pharmaceutical care. Am J Hosp Pharm. 1990 Mar;47(3):53343.
2. Zuidlaren. Classification for drug related problems:(revised 14-01-2010vm) V6.2. 2003-2010 Pharmaceutical Care Network Europe Foundation; Nov. 2009 November 2009 and January 2010. p. 9.

3. McCombs JS, Liu G, Shi J, Feng W, Cody M, Parker JP, et al. The Kaiser Permanente/USC Patient Consultation Study: change in use and cost of health care services. Am J Health Syst Pharm. 1998 Dec 1;55(23):2485-99.

4. Fernandez-Llimos F, Tuneu L, Baena MI, Garcia-Delgado A, Faus MJ. Morbidity and mortality associated with pharmacotherapy. Evolution and current concept of drug-related problems. Curr Pharm Des. 2004;10(31):3947-67.

5. Moyen E, Camire E, Stelfox HT. Clinical review: medication errors in critical care. Crit Care. 2008;12(2):208.

6. van den Bemt PM, Egberts TC, de Jong-van den Berg LT, Brouwers JR. Drug-related problems in hospitalised patients. Drug Saf. 2000 Apr;22(4):321-33.

7. J.Cipolle R. pharmaceutical care practices: the clinician's Guide, 3rd Edition. Minnocitta.

8. Feinleib M, Ingster L, Rosenberg H, Maurer J, Singh G, Kochanek K. Time trends, cohort effects, and geographic patterns in stroke mortality--United States. Ann Epidemiol. 1993 Sep;3(5):458-65.

9. Gaziano TA. Cardiovascular disease in the developing world and its cost-effective management. Circulation. 2005 Dec 6;112(23):3547-53.

10. Oyoo GO, Ogola EN. Clinical and socio demographic aspects of congestive heart failure patients at Kenyatta National Hospital, Nairobi. East Afr Med J. 1999 Jan;76(1):23-7.

11. Antony KK. Pattern of cardiac failure in Northern Savanna Nigeria. Trop Geogr Med. 1980 Jun;32(2):118-25.

12. Tantchou Tchoumi JC, Ambassa JC, Kingue S, Giamberti A, Cirri S, Frigiola A, et al. Occurrence, aetiology and challenges in the management of congestive heart failure in subSaharan Africa: experience of the Cardiac Centre in Shisong, Cameroon. Pan Afr Med J. 2011;8:11.

13. Alarouj M, Bennakhi A, Alnesef Y, Sharifi M, Elkum N. Diabetes and associated cardiovascular risk factors in the State of Kuwait: the first national survey. Int J Clin Pract. 2013 Jan;67(1):89-96.

14. Ernst FR, Grizzle AJ. Drug-related morbidity and mortality: updating the cost-of-illness model. J Am Pharm Assoc (Wash). 2001 Mar-Apr;41(2):192-9.

15. Cardone KE, Bacchus S, Assimon MM, Pai AB, Manley HJ. Medication-related problems in CKD. Adv Chronic Kidney Dis. 2010 Sep; 17(5):404-12.

16. Classen DC, Pestotnik SL, Evans RS, Lloyd JF, Burke JP. Adverse drug events in hospitalized patients. Excess length of stay, extra costs, and attributable mortality. JAMA. 1997 Jan 2229;277(4):301-6.

17. Stafford AC, Tenni PC, Peterson GM, Jackson SL, Hejlesen A, Villesen C, et al. Drug-related problems identified in medication reviews by Australian pharmacists. Pharm World Sci. 2009 Apr;31(2):216-23.

18. Koh Y, Fatimah BM, Li SC. Therapy related hospital admission in patients on polypharmacy in Singapore: a pilot study. Pharm World Sci. 2003 Aug;25(4):135-7.

19. Leendertse AJ, Egberts AC, Stoker LJ, van den Bemt PM. Frequency of and risk factors for preventable medication-related hospital admissions in the Netherlands. Arch Intern Med. 2008 Sep 22;168(17):1890-6. 


\section{Indo Global Journal of Pharmaceutical Sciences, 2015; 5(1): 26-39}

20. Patel P, Zed PJ. Drug-related visits to the emergency department: how big is the problem? Pharmacotherapy. 2002 Jul;22(7):915-23.

21. Dago Martinez A, Arcos Gonzalez P, Alvarez de Toledo Saavedra F, Baena Parejo MI, Martinez Olmos J, Gorostiza Ormaetxe I. [Risk indicators of preventable morbidity related to drug utilization]. Gac Sanit. 2007 Jan-Feb;21(1):29-36.

22. Bates DW, Teich JM, Lee J, Seger D, Kuperman GJ, Ma'Luf $\mathrm{N}$, et al. The impact of computerized physician order entry on medication error prevention. J Am Med Inform Assoc. 1999 Jul-Aug;6(4):313-21.

23. Bedouch P, Allenet B, Grass A, Labarere J, Brudieu E, Bosson JL, et al. Drug-related problems in medical wards with a computerized physician order entry system. J Clin Pharm Ther. 2009 Apr;34(2):187-95.

24. Munger MA. Polypharmacy and combination therapy in the management of hypertension in elderly patients with comorbid diabetes mellitus. Drugs Aging. 2010 Nov 1;27(11):87183.

25. Koh Y, Kutty FB, Li SC. Drug-related problems in hospitalized patients on polypharmacy: the influence of age and gender. Ther Clin Risk Manag. 2005 Mar;1(1):39-48.

26. Yusuff KB, Tayo F. Frequency, types and severity of medication use-related problems among medical outpatients in Nigeria. Int J Clin Pharm. 2011 Jun;33(3):558-64.

27. Claydon-Platt K, Manias E, Dunning T. Medication-related problems occurring in people with diabetes during an admission to an adult teaching hospital: a retrospective cohort study. Diabetes Res Clin Pract. 2012 Aug;97(2):223-30.

28. Roccatagliata D, Avanzini F, Monesi L, Caimi V, Lauri D, Longoni $\mathrm{P}$, et al. Is global cardiovascular risk considered in current practice? Treatment and control of hypertension, hyperlipidemia, and diabetes according to patients' risk level. Vasc Health Risk Manag. 2006;2(4):507-14.

29. Aburuz SM, Bulatova NR, Yousef AM, Al-Ghazawi MA, Alawwa IA, Al-Saleh A. Comprehensive assessment of treatment related problems in hospitalized medicine patients in Jordan. Int J Clin Pharm. 2011 Jun;33(3):501-11.

30. Andreazza RS, Silveira De Castro M, Sippel Koche P, Heineck I. Causes of drug-related problems in the emergency room of a hospital in southern Brazil. Gac Sanit. 2011 NovDec;25(6):501-6.

31. Kim AS, Johnston SC. Global variation in the relative burden of stroke and ischemic heart disease. Circulation. 2011 Jul 19;124(3):314-23.

33. Misganaw A, Mariam DH, Araya T. The double mortality burden among adults in Addis Ababa, Ethiopia, 2006-2009. Prev Chronic Dis. 2012;9:E84.

34. Al Salmi Z. Clinical Audit of Pharmaceutical Care provided by a Clinical Pharmacist in Cardiology and Infectious Disease in-patients at the Royal Hospital, Muscat/Oman. Oman Med J. 2009 Apr;24(2):89-94.

35. Zaman Huri H, Fun Wee H. Drug related problems in type
2 diabetes patients with hypertension: a cross-sectional retrospective study. BMC Endocr Disord. 2013 Jan $7 ; 13(1): 2$.

36. Krahenbuhl-Melcher A, Schlienger R, Lampert M, Haschke M, Drewe J, Krahenbuhl S. Drug-related problems in hospitals: a review of the recent literature. Drug Saf. 2007;30(5):379-407.

37. Blix HS, Viktil KK, Reikvam A, Moger TA, Hjemaas BJ, Pretsch P, et al. The majority of hospitalised patients have drugrelated problems: results from a prospective study in general hospitals. Eur J Clin Pharmacol. 2004 Nov;60(9):651-8.

38. Courtman BJ, Stallings SB. Characterization of drug-related problems in elderly patients on admission to a medical ward. Can J Hosp Pharm. 1995 Jun;48(3):161-6.

39. Beers $\mathrm{MH}$. Explicit criteria for determining potentially inappropriate medication use by the elderly. An update. Arch Intern Med. 1997 Jul 28;157(14):1531-6.

40. Bor A, Matuz M, Doro P, Viola R, Soos G. [Drug-related problems in the elderly]. Orv Hetil. 2012 Dec 8;153(49):192636.

41. Cunningham G, Dodd TR, Grant DJ, McMurdo ME, Richards RM. Drug-related problems in elderly patients admitted to Tayside hospitals, methods for prevention and subsequent reassessment. Age Ageing. 1997 Sep;26(5):375-82.

42. Mekonnen AB, Yesuf EA, Odegard PS, Wega SS. Implementing ward based clinical pharmacy services in an Ethiopian University Hospital. Pharmacy Practice. 2013;11(1):51-7.

43. Blix H, Viktil K, Reikvam Å, Moger T, Hjemaas B, Pretsch $\mathrm{P}$, et al. The majority of hospitalised patients have drug-related problems: results from a prospective study in general hospitals. European Journal of Clinical Pharmacology. 2004 2004/11/01;60(9):651-8.

44. Effect of Enalapril on Survival in Patients with Reduced Left Ventricular Ejection Fractions and Congestive Heart Failure. New England Journal of Medicine. 1991;325(5):293302.

45. Wile D. Diuretics: a review. Ann Clin Biochem. 2012 Sep;49(Pt 5):419-31.

46. Ezekowitz J, McAlister FA, Humphries KH, Norris CM, Tonelli M, Ghali WA, et al. The association among renal insufficiency, pharmacotherapy, and outcomes in 6,427 patients with heart failure and coronary artery disease. J Am Coll Cardiol. 2004 Oct 19;44(8):1587-92.

47. Uchiyama S. [Antiplatelet therapy: update in secondary stroke prevention]. Brain Nerve. 2013 Jul;65(7):771-82.

48. Cruickshank JM. Beta-blockers and heart failure. Indian Heart J. 2010 Mar-Apr;62(2):101-10.

49. Viktil KK, Blix HS, Moger TA, Reikvam A. Interview of patients by pharmacists contributes significantly to the identification of drug-related problems (DRPs). Pharmacoepidemiol Drug Saf. 2006 Sep;15(9):667-74.

ID: 101610675) indexed and abstracted in EMBASE(Elsevier), SCIRUS(Elsevier),CABI, CAB Abstracts, Chemical Abstract Services(CAS), American Chemical Society(ACS), Index Copernicus, EBSCO, DOAJ, Google Scholar and many more. For further details, visit 